\title{
Anti-BCMA Antibody-drug Conjugate AMG 224
}

National Cancer Institute

\section{Source}

National Cancer Institute. Anti-BCMA Antibody-drug Conjugate AMG 224. NCI

Thesaurus. Code C162528.

An antibody-drug conjug ate (ADC) comprised of an anti-human B-cell maturation antigen (BCMA) immunog lobulin G1 (IgG1) antibody conjug ated via the noncleavable linker 4-(Nmaleimidomethyl) cyclohexane-1-carboxylate (MCC), to the cytotoxic maytansinederivative, DM1, with potential antineoplastic activity. Upon administration, the monoclonal antibody moiety of AMG 224 selectively binds to BCMA expressed on the surface of tumor cells. Upon internalization, the DM1 moiety binds to tubulin, thereby disrupting microtubule assembly/disassembly dynamics and inhibiting both cell division and proliferation of tumor cells that express BCMA. BCMA, a receptor for a proliferationinducing ligand (APRIL) and B-cell activating factor (BAFF), is a member of the tumor necrosis factor (TNF) receptor superfamily (TNFRSF)and plays a key role in plasma cell survival; it is found on the surfaces of plasma cells and overexpressed on malignant plasma cells. 